\title{
Justin Green y el surgimiento del cómic autobiográfico
}

\author{
IRENE COSTA MENDIA
}

Irene Costa Mendia (1985) es licenciada en Historia del arte en la UPV-EHU. Centra su investigación para la tesis doctoral en torno a los cómics autobiográficos. Ha escrito reseñas y artículos en los fanzines La Gallina Vasca, RumblE!! , en la revista online Mamajuana, en las páginas web Tebeosfera y I'm the mocker y en el boletín cultural Anelier.

\section{RESUMEN}

El siguiente artículo estudia los orígenes del cómic autobiográfico. El objetivo del estudio es contextualizar la aparición de este tipo de cómic en el seno de la cultura del comix underground. Describir un panorama sociocultural y determinar los diferentes factores que posibilitaron el desarrollo de la autobiografía en el cómic. Nos centraremos en la obra de Justin Green, Binky Brown conoce a la Virgen María (considerada la primera obra autobiográfica en la historia del cómic estadounidense) y en las reacciones que causó en los dibujantes de la época. Partimos de la premisa de que, en un contexto de persecución y censura que se cebaba, especialmente, en los cómics, unos autores supieron combinar la sátira con los principios contestatarios heredados de la contracultura, aventurándose a romper tabúes, entre los que se encontraba la autobiografía.

\begin{abstract}
This paper studies the origins of autobiographical comic. The aim of the study is to contextualize the emergence of this type of comic in the bosom of the culture of the underground comix. Describing a cultural landscape and specifying the different factors that enabled the development of autobiography in the comic. We will focus on the work of Justin Green, Binky Brown Meets the Holy Virgin Mary (considered the first autobiographical work in the history of the American comics) and in the reactions it caused in the draftsmen of that time. We assume that, in a context of persecution and censorship that was focused, specially, in the comics, a few authors could combine the satire with the rebellious principles inherited from the counterculture, risking to break taboos, among which was the autobiography.
\end{abstract}

CuCo, Cuadernos de cómic número 1. Septiembre de 2013

CuCoEstudio 
Para Jack Jackson, ${ }^{1}$ un legado importante que dejaron al cómic los dibujantes underground fue la destrucción de las barreras de lo representable. ${ }^{2}$ Recordando a los dibujantes la libertad total que tenían para expresarse en el papel y contar todo tipo de historias. Uno de los protagonistas que llevó a cabo esta revolución fue Justin Green, que se aventuró a narrar episodios inspirados en sus vivencias desde la infancia a través de su alter ego Binky Brown.

En los últimos años, el cómic autobiográfico se ha asentado como una corriente importante que sigue aportando innovadoras visiones del medio y narrando relatos muy diferentes, tan diversos que tal vez sea un error tratar de encajarlos todos en un solo género. Nos parece interesante profundizar en el momento en el que empezaron a surgir este tipo de relatos y en los factores que motivaron su aparición.

\section{$\underline{\text { Los cómics en el punto de mira: la censura del Comic Code Authority }}$}

Durante los años cincuenta existía un mercado exitoso en torno al cómic de superhéroes, con autores de la talla de Jack Kirby y Will Eisner. Pero, durante esta década comienzan a proliferar otros géneros como el horror, el romance, el crimen, el bélico, la cienciaficción o el western. Estas historias apelaban a un público adulto, sin embargo, el cómic seguía considerándose un medio infantil.

En la sociedad estadounidense de los años cincuenta estaba fuertemente anclada la imagen de los padres como protectores de la moral de sus hijos. Los medios contribuían a atemorizar a los padres hablando de las tentaciones a las que la juventud tenía que hacer frente, sembrando la desconfianza y proclamando que la juventud era

\footnotetext{
${ }^{1}$ Jack Jackson (Pandora, Texas, 1941), escritor, historiador y dibujante de cómics, fue uno de los creadores de Rip Off Press, una de las primeras editoriales underground, en 1969.

${ }^{2}$ Cita extraída de entrevistas grabadas de los archivos de Patrick Rosenkranz. Disponible on line en: MRREBELVISIONS1. (14/05/2009). Rebel Visions Trailer 2009 [Archivo de vídeo] http://www.youtube.com/watch?v=1sNCmqLdY6Y
}

CuCo, Cuadernos de cómic número 1. Septiembre de 2013

CuCoEstudio 
potencialmente criminal si no se la controlaba. ${ }^{3}$ Comenzó así una búsqueda de los culpables de la corrupción de los niños, y es entonces cuando se fijaron en los cómics. En 1954, Fredric Wertham reafirmó la persecución a los comic-books con su libro Seduction of the Innocent. Argumentaba que la lectura de cómics incitaba a los jóvenes a la delincuencia, por sus contenidos explícitos de sexo, violencia y ofensas varias a las autoridades, la moral y el buen gusto.

Las editoriales comenzaron a recibir críticas y, antes de que se creasen medidas legales para atacarlos, decidieron crear su propio órgano censor, la Comic Magazine Association of America. En 1955 impusieron el Comics Code Authority, un código orientado a controlar el contenido de los comic-books. El material de aquellos editores de la asociación que no contase con la aprobación de este órgano censor no era aceptado por las principales distribuidoras.

La censura se centraba en diferentes aspectos muy significativos. Se aplicaba, por una parte, a cualquier representación de desnudos y escenas sexuales. Quedaba prohibida cualquier historia en la que se hiciese burla o se diese mala imagen de las autoridades. Escenas de "excesiva violencia” eran rechazadas. Cualquier historia que se refiriese a conflictos sociales era motivo de sospecha y debía ser revisada, por lo que los temas raciales, de clases y de género eran también censurables. Cualquier postura crítica con respecto a la educación, la religión o la política eran automáticamente descartadas.

De las primeras cosas que hizo la asociación fue crear una cláusula que prohibía palabras como "terror", "horror" o "bizarro" en las cubiertas de los cómics. Esto atentaba directamente contra las series de la editorial EC Comics (Entertaining Comics)

\footnotetext{
3 Refiriéndose a los padres y las asociaciones relacionadas con la infancia y adolescencia en la Norteamérica de los años cincuenta, Burkhart comentaba: "As in other periods of American history, these upholders of tradition bemoaned a developing separation between parental aspirations and children's behavior. They understood that despite all the postwar enthusiasm for family life, the American family itself now exercised less influence in the cultural formation of youngsters". Extraído de: BURKHART, G. J. A cicle of outrage. America's reaction to the juvenile delinquent in the 1950s. Oxford University Press, New York, 1986, p. 17.
} 
dirigida por Willian Gaines ${ }^{4}$, que escribía todas las historias junto a Al Feldstein (dibujó, editó y escribió historietas de terror para EC entre los años 1946 y 1953). Ambos inventaban tramas cada vez más sangrientas en las que combinaban el terror con el humor. El código censuró también los zombis, los vampiros y los hombres lobo. EC Comics era rentable gracias a series de terror como The Vault of Horror. Mad Magazine, capitaneada por Harvey Kurtzman, fue la única publicación de este sello que se pudo seguir publicando debido a su formato de revista. Willian Gaines fue perseguido por la opinión pública, tachado como el editor más amoral de América. Gaines defendió su posición con las siguientes palabras:

\begin{abstract}
What are we afraid of? Are we afraid of our own children? Do we forget that they are citizens, too, and entitled to select what to read or do? Do we think our children are so evil, so simple minded, that it takes a story of murder to set them to murder, a story of robbery to set them to robbery ? $^{5}$
\end{abstract}

Algunas editoriales como Gold Key y Dell Comics siguieron publicando al margen del sello, pero la mayoría adaptaron sus contenidos o cerraron. A principios de los sesenta el panorama de la industria del comic-book estaba en decadencia.

\title{
Estallido de libertad, la prensa underground
}

A finales de la década, el medio, que había sido mutilado y atrofiado por la censura, recibió un nuevo impulso liberador procedente de circuitos no comerciales. Los comix underground surgen en la costa oeste de Norteamérica, a finales de los años sesenta, más concretamente en San Francisco, a raíz de la prensa underground y de la subcultura psicodélica (también se crearon escenas interesantes en Nueva York y Chicago). La

\footnotetext{
${ }^{4}$ Tras la muerte del creador de EC Comics, Max Gaines, la editorial fue dirigida por su hijo William Gaines desde 1947 hasta su muerte en 1992.

${ }^{5}$ Fragmento extraídos de las declaraciones de Gaines en el Subcomité del Senado sobre la delincuencia juvenil, en Nueva York (1954). Se conserva la pista de audio del juicio entero en los fondos del archivo de la WNYC. Disponible on line en http://www.wnyc.org/blogs/neh-preservationproject/2012/aug/27/senate-subcommittee-juvenile-delinquency-ii/
}

CuCo, Cuadernos de cómic número 1. Septiembre de 2013

CuCoEstudio 
juventud de la época estaba inmersa en la cultura televisiva, el rock psicodélico, los comic-books y las drogas alucinógenas. A esto se sumaba toda la politización creada en torno a la guerra de Vietnam que se había iniciado en 1955.

En un momento en el que el LSD era accesible para la población e incluso se recetaba de forma legal en ciertos casos, se desarrolló en San Francisco todo un movimiento artístico en torno a la cultura de la droga. Los colores saturados e hipnóticos y las formas distorsionadas y orgánicas emulaban estados alterados de la percepción. Muchas bandas de rock encargaban carteles para sus conciertos. La industria creada en torno a estas imágenes y la popularidad que adquirieron estos carteles facilitó canales de distribución que el comix supo aprovechar.

En el ámbito de la producción de cómics, hay que resaltar ciertos factores determinantes en la popularización de las obras. La prensa underground surge en 1965, cuando los avances en la impresión de Offset facilitaron la producción de tiradas cortas a un bajo coste. Las máquinas de litografía eran más pequeñas que las de antaño, más fáciles de manejar por una sola persona. No hacía falta tener un gran equipo o una gran cantidad de dinero para poder crear una imprenta. Entre los años 1965 y 1966 se fundaron en San Francisco diferentes editoriales como L.A. Free Press, Berkeley Barb y East Village Other. Más adelante se creaba San Francisco Oracle. Se formaron pequeños grupos que funcionaban sin necesidad de patrocinadores que aportasen dinero y condiciones. De este modo surgió, en poco tiempo, toda una industria nueva en torno a los cómics autoeditados. Los avances en la forma de edición y distribución de la prensa underground y el mercado en torno al arte psicodélico posibilitaron que San Francisco se convirtiese en la meca del comix underground.

Lejos de los canales de distribución tradicionales, el clima inspiraba a la libertad creativa, al todo vale. Existía, entre los dibujantes, cierta postura de liberadores del medio, actuaban conscientes de estar reaccionando frente a la campaña de desprestigio que sufrió el cómic en la década de los cincuenta, cuando la mayoría de ellos eran niños. Permanecía vivo el recuerdo de la censura que mutiló drásticamente la posibilidad de 
tratar muchos temas reduciendo los cómics a panfletos dirigidos a los "niños bien". Eran conscientes de que sus obras mostraban contenidos ilegales censurados durante años. Estos temas tabú se convirtieron en materia prima por explorar. La palabra "comix" con la que se empezó a designar a estas publicaciones las diferenciaba de los cómics comerciales. La "x", además, hacía referencia a todo el material ilegal que contenían sus páginas. ${ }^{6}$

La contracultura, que arrancó en la década de los cincuenta con los autores de la generación beat, había generado una actitud inquieta y crítica con el statu quo. Surgieron nuevas preocupaciones entre la juventud, como la búsqueda de nuevas espiritualidades o la preocupación por el medioambiente y la paz mundial. Se generalizó una urgencia por transformar la sociedad entera desde sus cimientos.

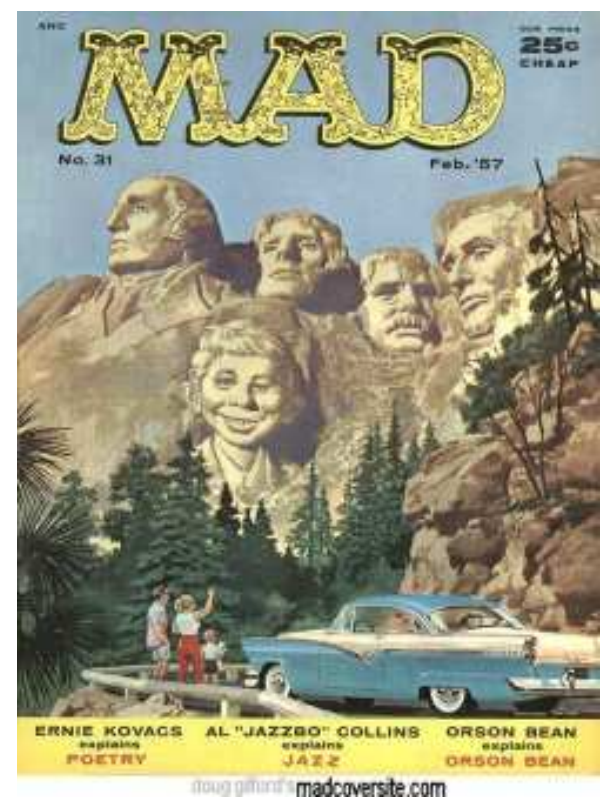

FIG. 1. Portada de $M a d$ n. 31 (Febrero, 1957), dibujada por Norman Indigo.

Los dibujantes underground reaccionaron contra el mainstream y llevaron a cabo su propia revolución a través de la sátira. Procedían de la brecha que dejó abierta

\footnotetext{
${ }^{6}$ El Refaye, E. Autobiographical comics. Life writing in Pictures. United Stated of America, University Press of Mississippi, 2012, p. 31.
}

CuCo, Cuadernos de cómic número 1. Septiembre de 2013 
Harvey Kurtzman. Son herederos de la forma de contar y el tipo de humor gamberro y osado que destilaban las historietas de $\mathrm{Mad}^{7}$ que eran capaces de parodiar desde personajes ficticios como Superman hasta políticos de la época. Gracias a autores como Kurtzman o Wallace Wood los jóvenes dibujantes vieron en el cómic un medio para vomitar toda la frustración acumulada durante los años de censura.

\section{$\underline{\text { Zap Comix, un punto de encuentro para los marginados }}$}

Diferentes dibujantes se fueron congregando en una misma zona, la Bay Area de San Francisco, donde la escena de la música rock estaba en plena efervescencia. Muchos dibujantes trabajaban creando imágenes psicodélicas para las bandas y armando carteles de conciertos para diferentes locales. Entre los locales más populares estaban Avalon y Fillmore. Los comix comenzaron a extenderse por diferentes puntos del país a través de circuitos marginales. No podían venderse en tiendas y quioscos porque todavía se exigía el sello de censura. De modo que los puntos de venta eran centros universitarios y redes de tiendas de ropa y artículos hippies conocidas como head shops (que se habían extendido por Estados Unidos y Canadá). Editoriales como Berkeley Barb, L.A. Free Press, Gothic Blimp Works, East Village Other y Yarrowtalks incluían cómics entre sus publicaciones. Por estas fechas, editores y autores empezaron a unir fuerzas y crearon el Underground Press Syndicate, con la intención de pactar un compromiso común para preservar la total libertad artística de los dibujantes. En cuestión de meses se había configurado una industria nueva regida por postulados opuestos a los de la industria mainstream en torno al cómic.

\footnotetext{
7 Mad, a su vez, tiene influencia de las llamadas Tijuana Bibles, publicaciones clandestinas con ilustraciones eróticas que parodiaban a las tiras cómicas de la prensa. Surgieron en los años veinte y su popularidad creció durante de la Gran Depresión.
} 
Robert Crumb se trasladó a San Francisco en 1967, huyendo del estilo de vida tradicional que le esperaba en su hogar en Filadelfia (Pensilvania). A finales del año creó la revista de cómics Zap Comix, que empezó a distribuir en la calle Haight de Bay Area, con la ayuda del editor Don Donahue y el poeta y editor de autores beat Charles Plymell. Para entonces ya existía un público interesado y líneas de distribución ávidas por recibir material innovador como el que ofrecía Crumb. Junto a Zap, existían otras publicaciones underground que incluían historietas como Bijou, Feds 'n' Heads y Yellow Dog. Zap sirvió de inspiración para otros que crearon pequeñas editoriales. A estos estudios llegaban cómics escritos y dibujados por el mismo autor, cosa poco habitual en la industria del cómic, tradicionalmente basada en un sistema que repartía los aspectos de la producción entre diferentes autores. La mayoría de estas publicaciones no eran entregas seriadas y muchas no pasaban del número uno. Las obras más exitosas eran reeditadas y se mantenían a la venta durante años.

Crumb fue un artista prolífico, creó diferentes personajes que llegarían a ser considerados iconos e incluso héroes generacionales como, por ejemplo, Mr. Natural, una parodia del gurú espiritual (prototipo que proliferaba en la época). Otro célebre personaje es Fritz the Cat. Fritz, en origen, era el gato de Crumb en su infancia, lo creó a modo de entretenimiento. En los sesenta este personaje se transformó en un gato universitario en constante estado de excitación, en otras ocasiones, era un hippie decadente. Schuman the Human era un personaje torturado en su eterna búsqueda del despertar de una conciencia mística. Crumb nunca llegó a sintonizar con la onda hippie. A través de estos personajes volcaba su sátira al movimiento del flower power del amor libre y la búsqueda de nuevas espiritualidades. Whiteman era un tipo de personaje diferente, representaba al hombre blanco de clase media que sabía exactamente cual era su papel en el mundo, era una parodia de su propio padre. La brutalidad policial, la experimentación con drogas, el feminismo y el racismo fueron también objetivos de su 
irónica mirada. Su trabajo se inscribe en la tradición satírica y crítica americana y en la línea de artistas como James Gillray $(1757-1815){ }^{8}$

$\mathrm{Su}$ material gustó mucho y enseguida se convirtió en una figura demandada. $\mathrm{Su}$ estilo recordaba a los dibujantes clásicos, pero el uso que hacía de este estilo era completamente nuevo, y esta mezcla llamó mucho la atención. Crumb creó a muchos de sus personajes a raíz de un viaje alucinógeno de LSD. En un principio los dibujos que hacía le resultaban inquietantes, pero pronto descubrió que gustaban y que, de alguna forma, capturaban la imaginación de la gente. Como sucedió con la historieta de "Keep on Trucking": "That was a drawing that came out of LSD trips, and the words came from a Blind Boy Fuller song from 1935. I drew it in my sketchbook and then for Zap. It sort of caught the popular imagination. It became a horrible popular thing". 9

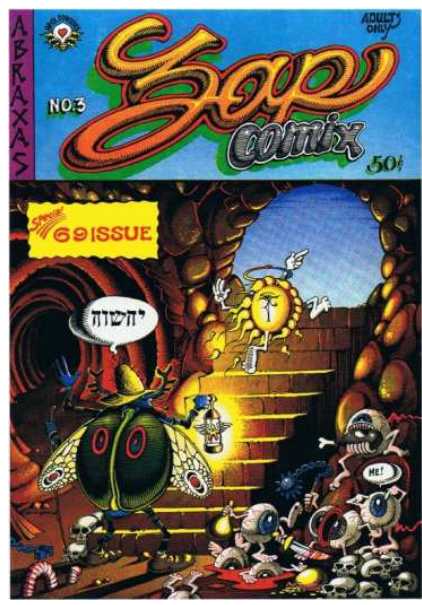

FIG. 2. Portada de Zap Comix n. 3 (Enero, 1968), dibujada por Rick Griffin.

\footnotetext{
${ }^{8}$ James Gillray fue un caricaturista británico conocido por sus sátiras a la monarquía inglesa y a los excesos del gobierno de Napoleón en Francia. En sus caricaturas jugaba con la exageración para criticar y ridiculizar a políticos de la época.

${ }^{9}$ WIDMER, T. "Robert Crumb, The Art of Comics, No.1", en The Paris Review, 2010. Disponible on line en http://www.theparisreview.org/interviews/6017/the-art-of-comics-no-1-r-crumb [Comprobado el 1109-2013]
} 
Crumb decidió continuar su revista y dar cabida a autores inéditos. El primero en sumarse fue S. Clay Wilson. Las historias de Wilson eran salvajes, llenas de violencia explícita. Los protagonistas eran gente de los bajos fondos, o piratas que celebraban interminables peleas y orgías que se extendían durante páginas enteras. Más adelante, se sumaron los cartelistas Rick Griffin y Víctor Moscoso, que trabajaban juntos por aquel entonces y habían empezado a incluir cómics en sus pósteres. Víctor y Rick, al igual que otros cartelistas, llevaron a cabo una transición al medio de la historieta al ver la popularidad que iba ganando entre el público y las posibilidades por explotar. A finales de 1968 entra Gilbert Shelton, que se haría famoso por sus icónicos personajes, los Freak Brothers, tres hippies en perpetuo estado de intoxicación que protagonizaban alocadas aventuras. Finalmente, los últimos en incorporarse fueron Robert Williams y Spain Rodríguez.

Había dos tendencias en las historietas de estos autores. Por una parte, tanto Crumb, como Shelton o Spain, buscaban personajes icónicos, mientras que Williams, Griffin y Moscoso, se interesaban más por parte visual de los cómics y menos por la narrativa. En el caso de Moscoso, sus cómics eran una extensión de sus pósteres, primaban los efectos visuales. Daba vida a extraños universos poblados por formas de vida mutantes, como en un sueño producido por un viaje de ácido.

En los inicios del underground no existía una presión monetaria que interfiriese en el resultado de los trabajos de estos autores, esto se debe a que no se esperaba que el oficio de historietista fuese rentable, dibujaban más por diversión que para obtener un beneficio. La vida, en general, era barata, vivieron un corto periodo de "bienestar" que fue un factor importante que contribuyó al sentimiento de total libertad artística. Crumb rechazó ofertas millonarias como una por parte de la revista Playboy, o el ofrecimiento que le hicieron los Rolling Stones para una de las portadas de sus discos. También declinó las propuestas de realizar películas o merchandising basados en sus dibujos. Se mantuvo en todo momento en los circuitos underground (salvo por un breve encuentro que tuvo con Kurtzman en la revista Help!, donde coincidió con dibujantes como Gilbert Shelton, Joel Beck y Jay Lynch). 
Esta ética de trabajo se relaciona con las premisas de la contracultura de la que todos ellos eran herederos. En palabras de Crumb: "We all read Jack Kerouac and we got all excited that we could have this freewheeling life. You don't worry about the money or where the next meal is coming from. You just go and do it."10

Gracias a Zap se reunieron diferentes autores y fue posible que, para principios de la década de los setenta, existiese una amplia variedad de comic-books como Slow Death, Man From Utopia, Young Lust, Tales from the Ozone y Feds 'n' Heads que convivían con Zap Comix, que seguía siendo la revista más solicitada. Editoriales como Print Mint, Rip Off Press o Apex Novelties, no alcanzaban a satisfacer la demanda que se había generado en torno a este material.

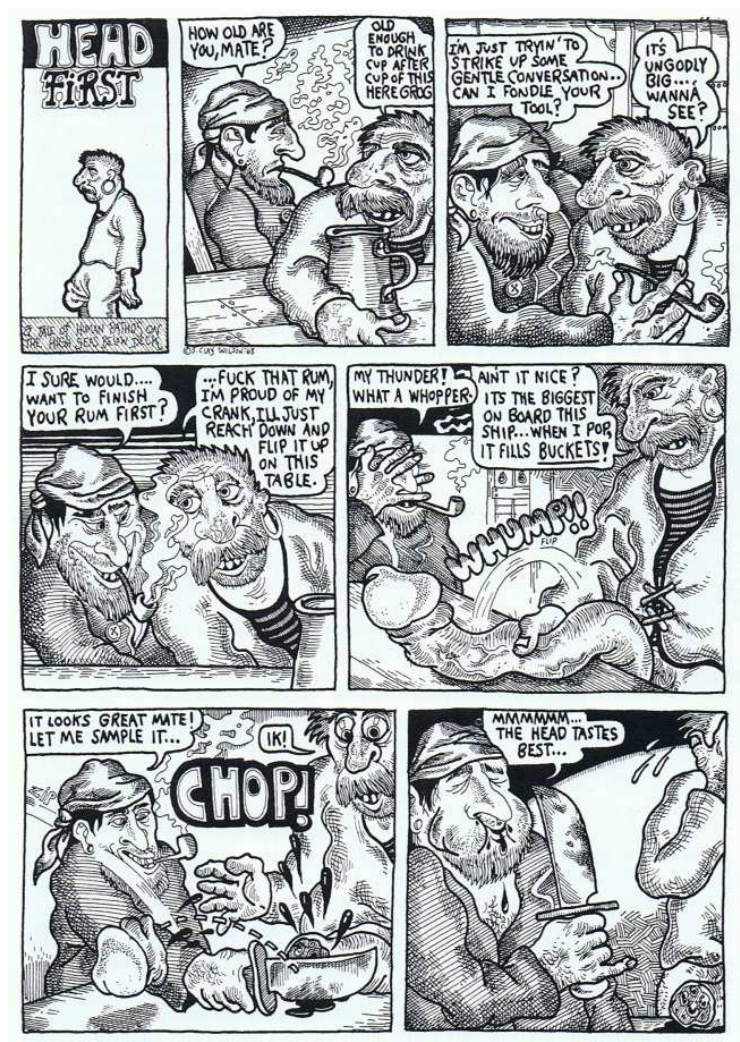

FIG. 3. "Head First", historieta de S. Clay Wilson para Zap Comix n. o 2 (1968). ${ }^{10}$ RosenKRANZ, P. Rebel Visions. The underground comix revolution 1963-1975. Seattle (Washington),
Fantagraphics Book, 2008, p. 71.

CuCo, Cuadernos de cómic número 1. Septiembre de 2013 


\section{Traspasando límites, anticipaciones de un cómic más personal}

Robert Crumb quedó impresionado por el salvajismo y la crudeza de las imágenes de las historietas de Wilson. "Head first" fue una de las primeras historietas que hizo Wilson para Zap en la que mostraba un pene gigante que era mutilado. Wilson veía su trabajo como una continuación de la labor que llevó a cabo EC Comics: "I always saw the underground comix movement as a sort of extension of EC's", "In my estimation we were taking it one step further by adding sex and drug and carnage and stuff.",11

A raíz de esta epifanía, Crumb se armó de valor para dibujar sus propias fantasías sexuales. Cuando la revista Zap iba por el tercer número, Wilson y Crumb crearon la revista Snatch, motivados por las críticas que empezaron a surgir por la introducción de temas sexuales. Crearon la revista para centrarse en estos temas y ver hasta dónde podían traspasar los límites de lo que el público era capaz de aceptar, antes de que se presentase la policía en sus casas. Las historietas eróticas y pornográficas creaban opiniones enfrentadas, desde la repulsa y la condena de aquellos que las consideraban denigrantes, hasta la expectación y admiración de otros lectores que veían reflejados en esas imágenes sus propios pensamientos y su sentido del humor.

${ }^{11}$ Ibíd., p. 145.

CuCo, Cuadernos de cómic número 1. Septiembre de 2013

CuCoEstudio 


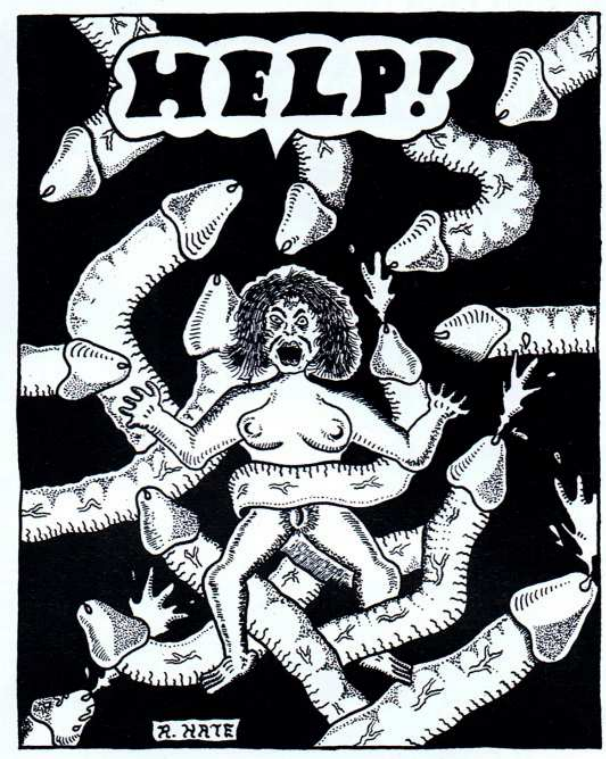

FIG. 4. Cunt Comics n. ${ }^{\text {1 }}$ (1969), por Rory Hayes.

Para el primer número de Snatch pidieron la colaboración de Rory Hayes que mandó una historieta especialmente brutal y soez, esto fascinó a los autores que seguían empeñados en forzar los límites de lo representable. Sin embargo, estas historietas levantaban llagas en otros sectores, y la obra de Hayes resultó ser especialmente polémica. Más aún cuando sorprendió a todos, poco más tarde, con Cunt Comics (1969). En este cómic daba rienda suelta a las inquietantes imágenes de sexo escatológico que producía su imaginación: "I took all this weird shit I had in the back of my head and threw it all out on paper. It was a relief, like coming. It's horrible. It's beautiful. I can't explain it."12

Wilson, que también fue interpelado por el contenido de sus historietas, hablaba así sobre los juicios que se desataban: "Just because you depict evil, doesn't mean you are evil," "People always get that confused. They expect me to be all the monsters I

${ }^{12}$ Ibíd., p. 133.

CuCo, Cuadernos de cómic número 1. Septiembre de 2013

CuCoEstudio 
draw. I say, 'No, I'm a repressed Victorian. I shuffle around here and drink my morning tea." 13

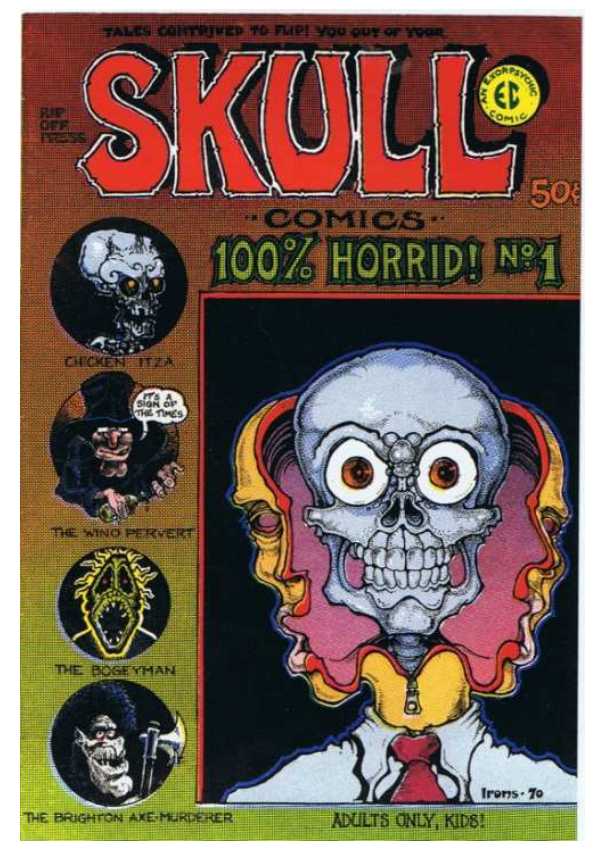

FIG. 5. Portada de Skull Comics n. 1 (1970), por Greg Irons.

Greg Irons fue uno de los primeros en representarse en sus historietas, pero consideró que era un error que su personaje fuese reconocible así que, años más tarde, daría con una formula que tendrá gran repercusión, buscó un alter ego animal con aspecto antropomorfo. De esta forma creó a Gregor, the Purple-Ass Baboon que apareció por primera vez en Wirtham's Comix \& Stories, en 1976. A través de este personaje volcó una encarnizada sátira de sí mismo. Greg dibujó la portada para el primer número de Skull Comics, revista creada por Gary Arlington con una marcada influencia del estilo de los cómics de EC. En los dibujos de Greg abundaban las referencias a calaveras y todo lo que remite a la iconografía en torno a la muerte; tema, en particular, que siempre le había inquietado sobremanera.

${ }^{13}$ Ibíd., p. 168.

CuCo, Cuadernos de cómic número 1. Septiembre de 2013

CuCoEstudio 
Por otra parte, Crumb, en su proceso de plasmar sus fantasías sexuales, comenzó a representarse a sí mismo hablando directamente a sus lectores. Revelando y revelándose sus propias fantasías y obsesiones. En este torrente volcó en tono satírico todos los estereotipos que anidaban en su cabeza. La polémica llegó con el número cuatro de Zap, en el que realizó una historia que saltó las alarmas de la censura, hablamos de "Joe Blow" en donde se retrataba a una familia media americana, que era perfecta en la superficie, pero estaba repleta de lujuria e incesto en la intimidad del hogar. El cómic fue perseguido casi inmediatamente después de ser publicado, y varios vendedores desde Berkeley a Nueva York fueron arrestados por tenerlo a la venta. ${ }^{14}$ Al parecer, Crumb había dado con un punto vulnerable del discurso social establecido. Había pervertido la familia de clase media blanca, agrediendo el "sueño americano".

Los comix aparecieron en el momento justo en el que la represión por parte del gobierno se enfrentaba a los crecientes movimientos de protesta populares. Las historietas estaban repletas de gestos en contra del orden. En 1968, Spain Rodríguez creó a Trashman, un rudo guerrillero que combatía a los opresores y conquistaba a las nenas. Trashman se convirtió en icono de la acción callejera, bajo el lema "Fight the Oppression!”. Gustó mucho entre el público juvenil crítico con las actuaciones del gobierno estadounidense en la guerra de Vietnam. En uno de los episodios, se incluyó a sí mismo como personaje haciendo una especie de cameo en un bar. Muchas de sus historietas estaban basadas en sus experiencias en Buffallo, Nueva York, donde participaba en el club de moteros Road Vulture Motorcycle Club.

${ }^{14}$ Ibíd., p. 143.

CuCo, Cuadernos de cómic número 1. Septiembre de 2013

CuCoEstudio 


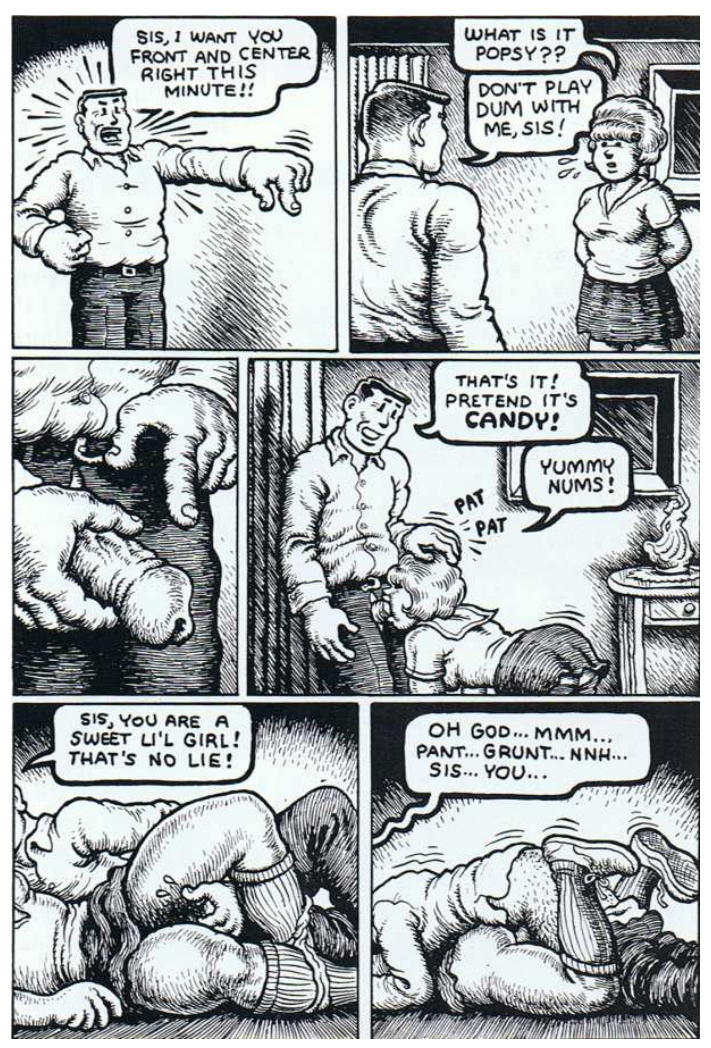

FIG. 6. "Joe Blow", historieta de Robert Crumb para Zap n. ${ }^{\circ} 4$ (1969).

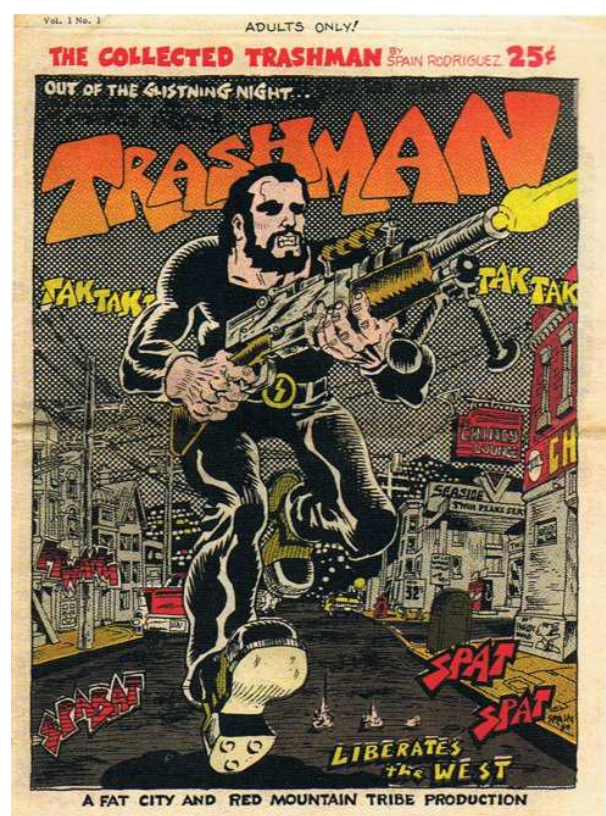

FIG. 7. Portada de The Collected Trashman (1968) por Spain Rodríguez.

CuCo, Cuadernos de cómic número 1. Septiembre de 2013 
Durante 1970 y 1971 estos autores vivieron momentos difíciles, el panorama político parecía inclinarse hacia la derecha y durante esos días llegaron a pensar que en cualquier momento la policía se presentaría en sus casas para arrestarles. En junio de 1973 la Corte Suprema de Estados Unidos acordó que cada comunidad tendría la libertad para determinar lo que se consideraba obsceno. ${ }^{15}$ Surgieron nuevos ataques al cómic desde la prensa. Muchas head shops dejaron de vender comix o cerraron su negocio. Sin embargo, para entonces ya existía un público consolidado y se habían creado tiendas especializadas donde tenían cabida algunas de estas publicaciones. Su popularidad, aun así, había descendido notablemente a mediados de los setenta.

\section{La incorporación de Justin Green}

Green nació en Chicago en 1945. A través de los cómics aprendió a dibujar, escribir y rotular. En 1963 ingresó en la escuela de Rhode Island donde comenzó haciendo pintura abstracta. Desde un principio le interesó también la corriente surrealista, tanto los autores europeos como los americanos. En aquella época no quería ser dibujante de cómics, el cómic no le parecía un medio lo suficientemente sofisticado y criticaba el formato: "I saw it as a slooppy lackadaisical kind of art form, beneath contemp, really". ${ }^{16}$ Sin embargo, durante el sexto grado tuvo su primer contacto con la publicación de cómics. Junto con su amigo Ricky Schwartz crearon una revista llamada Step-Up, con influencias de las revistas Mad y Panic. Desde la escuela de Rodhe Island, Justin accedió a un programa de estudios europeos que le llevaría hasta Roma en 1967, donde pasó un año. No sentía mucha afinidad con el arte renacentista y se centró en

15 VV. AA. The apex treasury of underground comics / edited by Susan Goodrick and Don Donahue; featuring, Willie Murphy, Bill Griffith, Art Spiegelman, Spain Rodriguez, Justin Green, Gilbert Shelton, R. Crumb, Shary Flenniken, Bobby London, Jay Lynch, Kim Deitch . The best of Bijou funnies / edited by Jay Lynch; introduction by Marty Pahls; featuring, Jay Lynch, Skip Williamson, Jay Kinney, Justin Green, Robert Crumb, Jim Osborne, Gilbert Shelton, Dan Clyne, Evert Geradts, Rory Hayes, Art Spiegelman and Kim Deitch. The best of Bijou funnies. London, Omnibus Press, 1981, p. 113.

${ }^{16}$ RosenKRANZ, P. Op. cit., p. 33. 
buscar las referencias artísticas con las que había crecido: la televisión estadounidense, las películas y los cómics. Estando en Italia se topó con una publicación que contenía una historieta de Crumb, que supuso para él un cambio radical en lo que sería su trayectoria artística.

The Word 'epiphany' gets tossed around a lot these days, but one of the few such moments in my life that I cherish is the moment I saw a rather grainy reprint of Crumb's 'Itzy and Bitzy'. It was a call of arms for me. I immediately started cartooning again; something I had done only in secret since high school. My abstract paintings suddenly became filled with images. ${ }^{17}$

En 1968, Green volvió a Estados Unidos para coger un trabajo como profesor ayudante en la Universidad de Syracuse. Por esa época abandonó la pintura abstracta y se metió de lleno en los cómics. "I started to cartoon like a madman. I worked 12 hours a day. The only time I went out of the house was to get some Murine for my eyes which were all swollen up and red." ${ }^{18}$ Mandó una historieta a Yellow dog llamada "The Drip" y luego hizo "A temporary Relapse", con la que finalmente experimentó el disfrute del oficio: "When I did the strip, I finally experienced the paroxysms of laughter that I'd had from Crumb strip a year and a half prior. I fell on the floor. So I knew there was something in cartooning for me. I got an immediate return from energy I put into it." 19

En 1969 se mudó a New Jersey donde entró en contacto con otros dibujantes y publicó en Gothic Blimp Works. Volvió a trasladarse a Boston donde continuó dibujando. Estos traslados estaban en relación con la política de reclutamiento que estaba en vigor y de la que Justin trataba de escapar. Casi todo el mundo tenía algún conocido que había resultado herido o había muerto en la guerra. Su último traslado lo llevó a San Francisco donde alquiló un local barato. Por entonces se podía malvivir como artista underground dedicando muchas horas diarias. A cambio, el autor se encontraba con una libertad absoluta para esparcir su creatividad y sus ideas. Entró en

\footnotetext{
${ }^{17}$ Ibíd., p. 94.

${ }^{18}$ Ibíd., p. 154.

${ }^{19}$ Ibíd.
}

CuCo, Cuadernos de cómic número 1. Septiembre de 2013 
contacto con todo el movimiento artístico que se estaba llevando a cabo. Green, que compartía varios principios antiautoritarios y también había sido fervoroso lector de Mad Magazine, quedó fascinado por el ímpetu de los dibujantes en su misión de reinventar los cómics y por lo novedoso de la situación, pues cada día surgían nuevas ideas.

\section{Binky Brown conoce a la Virgen María}

En 1971 el público lector de comix se había extendido. Uno de los factores que intervino fue el espacio publicitario que usó la industria del sexo en las publicaciones, que funcionó como reclamo para un tipo de público. Políticamente ciertas posturas se habían radicalizado, diferentes sectores de la sociedad reclamaban medidas más duras que las propuestas de paz del movimiento hippie. Sectores como marxistas de la línea radical, grupos por la liberación de las mujeres y organizaciones en torno a minorías sociales proclamaron la prensa underground como su medio de expresión.

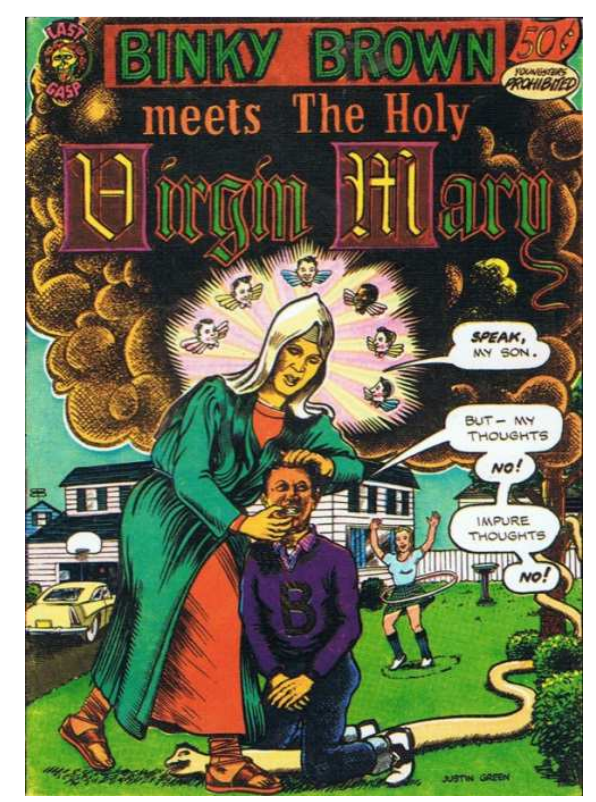

FIG. 8. Portada de Binky Brown Meets the Holy Virgin Mary (1972), por Justin Green. 
Arrastrando una carga de culpabilidad generada por el conflicto bélico, Justin decidió que debía contar temas serios en sus historietas y escogió hablar de sí mismo. En un momento en el que la magia, el tarot y el misticismo eran muy populares, cuando todavía no concebía el tipo de historia que iba a realizar, dibujó lo que luego sería la portada, basándose en el símbolo de "la Fortaleza" del Tarot. La contraportada se basaba en la carta de "la Torre" que aludía a la destrucción y la trasformación. Estas imágenes las tuvo a la vista durante todo el proceso de creación de Binky Brown. Acuciado por la necesidad de contar su historia, se enfrentó a la obra como si se tratase de una terapia particular. Contemplar estos símbolos, en el proceso, le armaba de fuerza para romper ciertos tabúes.

En el cómic relató episodios de su infancia y adolescencia, centrándose en los problemas que lo obsesionaban y en los rituales que comenzó a realizar desde muy temprano para aliviar su malestar. Justin luchaba su particular Vietnam contra su neurosis y el discurso confesional ${ }^{20}$ encajaba en esta conjunción de neurosis y catolicismo. El crítico Waldemar Janusczak en su crítica a la exposición realizada en 1984, en Londres, sobre las relaciones entre el arte de galería y los cómics, describió de esta forma la irrupción del discurso confesional en los cómics:

\begin{abstract}
Cuando los neuróticos se apropiaron del cómic, fuimos testigos del matrimonio ideal entre la forma y el contenido. Subvirtieron la inocencia de este y llenaron sus bocadillos de pensamientos con miserables soliloquios, repletos de sentimientos de culpa. El cómic resultó ser un medio espléndido para las confesiones. Y nosotros, el público, nos vimos llamados a cumplir con el deber de un sacerdote católico. ${ }^{21}$
\end{abstract}

${ }^{20}$ Según Michel Foucault en Historia de la sexualidad. Vol.1. La voluntad de saber, el discurso
confesional ha sido, desde la Edad Media hasta nuestros días (se constituyó dentro de la tradición y
católica y se secularizó durante el siglo XIX a través del discurso psiquiátrico), la forma de discurso
imperante en torno al sexo en la tradición occidental. 21 VV. AA. Supercómic. Mutaciones de la novela gráfica contemporánea. Madrid, Errata Naturae Editores, 2013, p. 28.

CuCo, Cuadernos de cómic número 1. Septiembre de 2013

CuCoEstudio 
S. Clay Wilson le hizo darse cuenta de que su estilo de dibujo tenía reminiscencias a imágenes que le quedaron grabadas en la infancia del El Catecismo de Baltimore (un misal católico para niños que incluía viñetas pedagógicas).

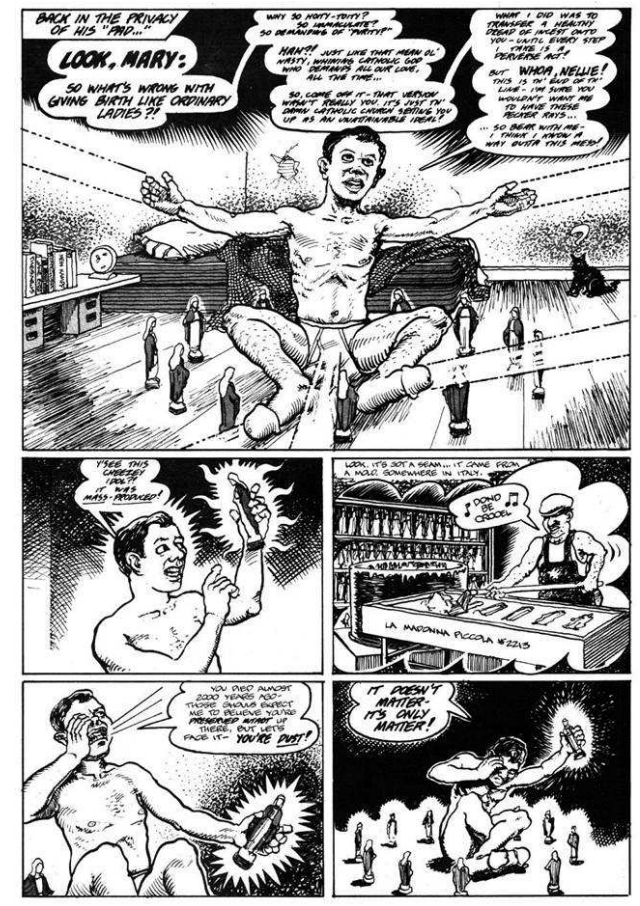

FIG. 9. Binky Brown Meets the Holy Virgin Mary (1972), por Justin Green.

Iba colgando las páginas en cuerdas de tender en su apartamento, de esta manera podía ver, al mismo tiempo, un panorama de la evolución de la historia y una visión de conjunto. Daba a cada página una entidad propia. Su ética de trabajo por entonces era diferente a la actual, no se trataba de la productividad sino del resultado, del mensaje. Podía estar trabajando cuatro o cinco días en una página y a continuación desecharla.

Justin no siguió el estilo clásico de otros dibujantes, ni empleó las normas prototípicas de lenguaje del cómic de entonces, sino que indagó en lo que el medio le ofrecía. La voz de los cartuchos, por ejemplo, le daba la posibilidad de establecer contradicciones entre el texto y lo que las imágenes muestran en las viñetas. El globo de pensamiento era para él una segunda voz que implicaba otra dimensión en la historia, lo que resultaba muy práctico para trasladar lo que ocurría en la cabeza de un niño católico 
que se cuestionaba constantemente lo que estaba haciendo y si era moralmente aceptable.

Esperaba que, de alguna forma, su trabajo tuviese un impacto en su vida real. La parte de sí mismo que estaba escribiendo el libro sabía que se trataba de un ritual, es decir, algo artificial. Pero, a través de ello, quedaba en evidencia que los rituales que él mismo venía haciendo desde niño eran, igualmente, motivados por temores ficticios. En la mente de Justin y en la de su alter ego Binky Brown, su naturaleza depravada se manifestaba en forma de rayos de luz de pecado que emanaban de todas sus extremidades. Si estos rayos, que se extendían kilómetros, impactaban contra algún objeto sagrado de la religión católica (estatuas de la Virgen María, especialmente) ocurrirían desgracias en su vida y en la de sus seres queridos. Cuando empezó el cómic tenía la esperanza de que, al terminar, estos delirios se desvaneciesen.

Aunque en general se le considere el creador del género autobiográfico en el cómic, Justin opina que no puede reclamar ese mérito, pues era el momento idóneo para la aparición de historias autobiográficas, y si no lo hubiese hecho él otro lo habría iniciado igual. Sin embargo, el mérito que se atribuye es el de haber dado aspecto gráfico por vez primera a lo que años después nombrarían como "trastorno obsesivocompulsivo", conocido en inglés con las siglas OCD (Obsessive Compulsive Disorder). Fue la primera vez que alguien mostraba gráficamente la evolución de una neurosis. Justin estaba empeñado en sacar adelante su relato y lo hizo a través de la ironía: "The scientologists say that all humour comes from exclusion or embarrassment, but I think there is a third kind of laughter, which is the laughter of freedom... the laughter of sudden discovery that you're above or beyond a conflict that once blocked you in". ${ }^{2}$

El humor forma parte de su aproximación catártica al relato de su vida, un punto clave en la lectura de su obra. La historia de Binky tiene episodios angustiosos, otros

\footnotetext{
${ }^{22}$ RosenkranZ, P. Op. cit., p. 170.
}

CuCo, Cuadernos de cómic número 1. Septiembre de 2013 
desgarradores, pero Justin, lejos de endulzarlos, reaccionó caricaturizando y ridiculizando a su alter ego en situaciones de gran crudeza.

\begin{abstract}
More and more I am trying to work with humour. I'm trying to respect the form and language of comix themselves. I believe that you can never put your fingers on why something makes you laugh, because the sound of laughter is the sound of astonishment. Laughter, like orgasm, like sneeze, is involuntary. Humor in its highest form is catharsis and purification. The more I confront myself through humor the less cruel and sensationalistic my work will become. Then I'll be able to reach a larger audience. ${ }^{23}$
\end{abstract}

Binky Brown Meets Holly Virgin Mary es una propuesta atrevida e inédita, cuarenta páginas de extensión para contar la historia de sus demonios personales. Pero se las arregló para convencer a los editores de Last Gasp y la obra se publicó en 1972.

\title{
El mundo conoce a Binky Brown
}

La obra tuvo una buena acogida desde el principio, la novedad que suponía para la historieta era evidente, Justin había dado con una interpretación clave de la historieta en esos momentos. La catarsis de su alter ego de tinta tuvo su reflejo en la catarsis de los lectores que se asomaba a sus intimidades.

Uno de los primeros en quedar fascinado por la obra fue Art Spiegelman, que visitó a Green durante el proceso de creación de la obra. "I'll never forget seeing the unpublished pages of Binky Brown hanging from a clothesline stretched around the drawing table and all through his living room back in 1971 and knowing I was seeing something new get born". ${ }^{24}$ Le sorprendió la determinación con la que Green contaba sus vergüenzas íntimas. El hallazgo le hizo plantearse su propio bagaje personal como material para sus cómics y aventurarse a dibujar las vivencias de sus padres. Ese mismo

23 VV. AA. The apex treasury of underground comics / edited by Susan Goodrick and Don Donahue; featuring, Willie Murphy, Bill Griffith, Art Spiegelman, Spain Rodriguez, Justin Green, Gilbert Shelton, R. Crumb, Shary Flenniken, Bobby London, Jay Lynch, Kim Deitch. London (New York), 1974, p. 88.

${ }^{24}$ RosenkranZ, P. Op. Cit. p. 170. 
año publicaba las primeras páginas de lo que más tarde sería Maus, para la revista Funny Animals. Era la primera vez que se dibujaban los horrores del holocausto en un cómic, con animales antropomorfos como protagonistas.

También fue decisiva esta obra para Aline Kominsky. Aline se dedicaba a la pintura expresionista y no le interesaban los cómics hasta el día que topó con la obra de Green. Binky Brown le hizo percatarse de que podía volcar su propia voz a través del cómic. Descubrió que era posible combinar su trabajo artístico con el odio a su madre, que era una de sus obsesiones en ese momento. En 1972 colabora en el primer número de la publicación Wimmen's Comix con la historieta “Goldie: A Neurotic Woman”. Más tarde se desmarcó de Wimmen's Comix y fundó su propia revista junto a Diane Noomin, Twisted Sisters. En la portada del primer número aparece Kominsky sentada en la taza del váter en la que, según ella, es donde tenía sus mejores reflexiones. Creó el personaje The Bunch que rompía todos los estereotipos femeninos, regodeándose en lo grotesco, riéndose de sus propios complejos y obsesiones.

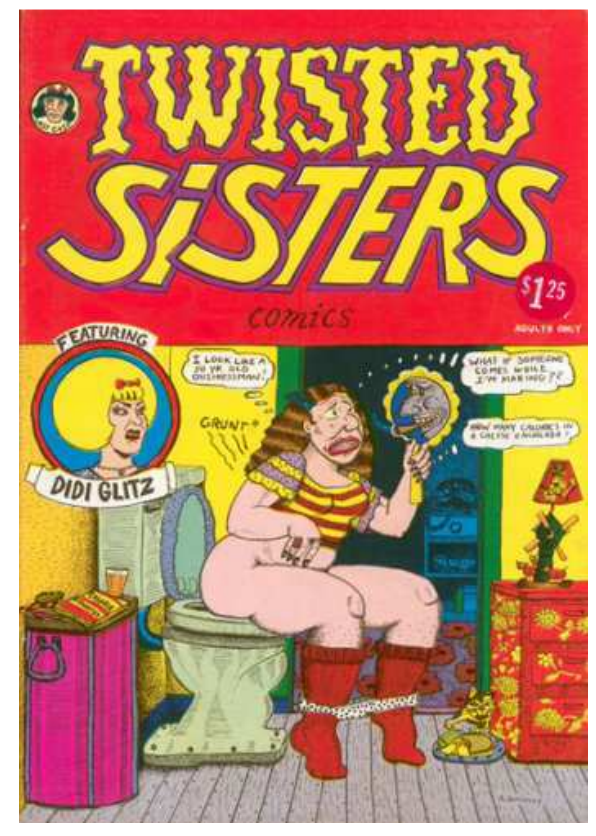

FIG. 10. Portada de Twisted Sisters n. ${ }^{\circ} 1$ (1976), por Aline Kominsky.

El cambio en la legislación que encrudeció la censura en 1973 y la persecución a las head shops contribuyó a que las ventas de comix descendiesen. Esto coincidió con 
que se publicaba mucho material, que no siempre era bueno, por otra parte. Fue un momento único pues se pudo publicar prácticamente cualquier cosa y eso posibilitó nuevas formas de concebir el medio.

En 1976, Harvey Pekar creó American Splendor, un cómic que publicaba anualmente y giraba en torno a su vida diaria, por aquel entonces trabajaba de archivador en Cleveland's Veteran's Administration Hospital. Fue la primera vez en la que un autor reunía un elenco de diferentes dibujantes para retratar historias sobre su rutina. En la lista de dibujantes que lo ilustraron se encuentran Robert Crumb, Spain Rodríguez, Joe Sacco, Alison Bechdel o Chester Brown, entre otros.

Jim Woodring, creador de la revista Jim (1980) en donde volcaba historietas inspiradas en experiencias oníricas, consideraba Binky Brown uno de los cómics que más le habían influido en diferentes aspectos de su vida y de su trabajo. Carol Tyler, humorista y pintora que indagó en la historia de su padre a través de su cómic You'll never know (2009) y Julie Doucet con su personaje Dirty Plotte a través del cual contaba su día a día, sus angustias, sueños y fantasías. Otra artista que se vio influenciada fue Phoebe Gloeckner. La primera vez que Gloeckner vio una imagen de contenido sexual fue a través de historietas de Crumb. Admiraba también a Kominsky y a Green, la belleza de las obras y la crudeza de los contenidos fueron una gran inspiración para sus cómics. Años después publicaría dos obras pseudoautobiográficas, A child's life and other stories (1998) y A teenager diary (2002). Joe Sacco comenzó a trabajar para Fantagraphics en 1986. La deriva de lo personal en el cómic tomó un nuevo rostro a través de sus crónicas periodísticas en primera persona. A partir de los ochenta en Canadá, el grupo de amigos formado por Seth, Chester Brown y Joe Matt, comenzaron a publicar sus propios comic-books que contenían historietas, en las que cada uno desarrolló un estilo diferente de aproximarse a la autobiografía.

A partir de 1975 serán la revista Weirdo, dirigida por Crumb la encargada de continuar la corriente underground, dando cabida además a artistas como Peter Bagge, Debbie Drechsler, Carol Tylor, Joe Matt, Julie Doucet y Dori Seda entre otros.

CuCo, Cuadernos de cómic número 1. Septiembre de 2013 


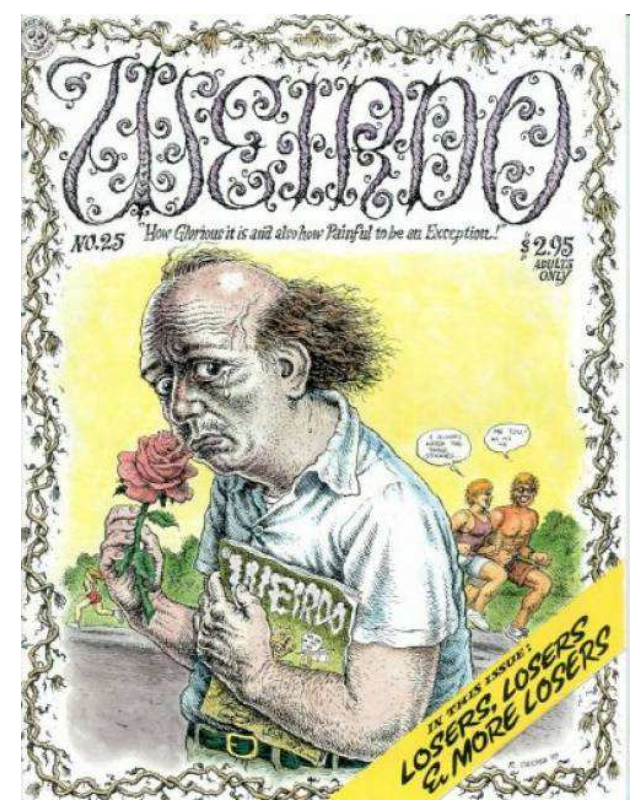

FIG. 11. Portada de Weirdo n. ${ }^{\circ} 25$ (1989), por Robert Crumb.

Cada vez más autores empiezan a dibujar relatos basados en vivencias personales. Durante los ochenta, siendo autor de una generación anterior a los autores underground, Will Eisner se declinó por la autobiografía, después de ver trabajos de Crumb y Green. En 1985 realizó The Dreamer, en 1991 To the Heart of Storm, The Name of the Game y dos historietas cortas: "A Sunset in Sunshine City”, y "The Day I Became a Professional".

Spiegelman creó la revista Raw junto con Françoise Mouly en 1980. La innovación que presentaba esta revista frente a otras era que se buscaba en autores que experimentasen con las posibilidades gráficas y que jugasen con cruces de diferentes lenguajes gráficos. Su búsqueda de nuevas visiones les llevó a publicar a autores de puntos dispares del globo (congoleños, españoles, argentinos, japoneses, italianos, francés, holandés, entre otros). Empleaban materiales asequibles y baratos, lo armaban trabajando mucho la parte del diseño y maquetación.

Los Hermanos Hernandez con Love \& Rockets forman parte de una transición hacia lo que se llama cómic alternativo, cuya revista de referencia era Raw. Sumergidos en la corriente que se llamó slice of life, con la que se pretendía contar historias de 
realidad cotidiana. Daniel Clowes se sumó a esta corriente con Ghost World (19931997).

El comic underground era ya una corriente con influencia internacional, que se extendió, sobre todo, en Europa. En palabras de Patrick Rosenkranz:

\begin{abstract}
In the midst of all this turmoil, a cadre of cartoonist succeeded in elevating comics to a medium of personal expression and unrestrained passion. Despite repression, rejection, and underfinancing, the comix industry thrived for a time and prepared the way for punk graphics, alternative comics, graphic novels, and other products in the small-press market today. ${ }^{25}$
\end{abstract}

\title{
Conclusiones
}

El deseo de transformación de la sociedad que se generalizó en los años sesenta, unido a la crítica al statu quo de la contracultura y a la desfragmentación de las percepciones de las drogas psicodélicas, anticipaban una serie de transgresiones que, con el comix, tomaron forma gráfica a través de la sátira en torno a temas tabú como lo escatológico, la muerte, el sexo, la violencia o las intimidades. Los dibujantes underground comenzaron a transgredir las normas que regulaban los contenidos de los cómics y comenzaron a utilizarlos como repulsivo social y como vehículo para expresarse.

La industria en torno a los pósteres psicodélicos, los avances en la imprenta Offset y los canales de distribución de la prensa underground posibilitaron que se crease una industria en torno al comix y que se expandiese y llegase a la gente.

Justin Green con su cómic Binky Brown, narró lo nunca narrado, inventando y jugando con las posibilidades del medio. Fue un ejercicio que vivió como una experiencia catártica, no solo él sino, también, otras personas que vieron su obra. A muchos autores les puso a dibujar desde otra perspectiva. Esta deriva personal tomó muchos caminos muy diferentes entre sí. Por ejemplo, en el caso de Hayes y Crumb, se

\footnotetext{
${ }^{25}$ Ibíd., p. 15.
}

CuCo, Cuadernos de cómic número 1. Septiembre de 2013 
centraban en las imágenes sexuales, en el caso de Irons en la muerte o, en el de Spain, en el desafío a las autoridades.

En Justin esta deriva personal le hizo ponerse cara a cara con su relación con el catolicismo y con el trastorno obsesivo-compulsivo. Son diferentes ejemplos de a dónde les llevó la ruptura de tabúes que estaban llevando a cabo. La catarsis del protagonista de Binky Brown conoce a la Virgen María refleja la de muchos que se habían criado en un ambiente alienante y opresivo y que encontraron en los cómics una forma de expresarse.

\section{Bibliografía}

BRAY, G. (11/06/13). Justin Green talks about graphic novel "Binky Brown”. Amadora, Portugal, 2012 [Archivo de vídeo]. Obtenido de https://www.youtube.com/watch?v=bcUy7GheB0Y

BURKHART, G. J. A cicle of outrage. America's reaction to the juvenile delinquent in the 1950s. Oxford University Press, New York, 1986.

CRUmb, R. El Gato Fritz. Obras completas de Robert Crumb. 5, Barcelona, La Cúpula, 1999.

—R. Crumb: Recuerdos y opiniones. Barcelona, Global Rythm, 2008.

El Refaye, E. Autobiographical comics. Life writing in Pictures. United Stated of America, University Press of Mississippi, 2012.

GARriocK, P. R. Masters of Comic-book Art Will Eisner, Harvey Kurtzman, Frank Bellamy, Richard Corben, Barry Windsor-Smith, Jean Giraud, Philippe Druillet, Wallace Wood, Robert Crumb, Victor Moscoso. London, Aurum Press, 1978.

CuCo, Cuadernos de cómic número 1. Septiembre de 2013 
GREEN, J. Binky Brown conoce a la Virgen María. Barcelona, Ediciones La Cúpula, 2011.

FoucAult, M. Historia de la sexualidad. 1-La voluntad del saber. Siglo Veintiuno Ediciones, México, 2009.

Morgan, H. "Notes for the course at École Européenne Supérieure de l'image in Angoulême, in 2010” (Master 1. Module: Le Roman Graphique).

RANDALL, J. "The Goblin Meets Binky Brown Who Met The Holy Virgin Mary", Goblin Magazine. Disponible on line en http://sonic.net/ goblin/Just.htm [Comprobado el 06-11-2012]

RosenKRANZ, P. Rebel Visions. The underground comix revolution 1963-1975. Seattle (Washington), Fantagraphics Books, 2008.

VV. AA. Supercómic. Mutaciones de la novela gráfica contemporánea. Madrid, Errata Naturae Editores, 2013.

VV. AA. The apex treasury of underground comics / edited by Susan Goodrick and Don Donahue; featuring, Willie Murphy, Bill Griffith, Art Spiegelman, Spain Rodriguez, Justin Green, Gilbert Shelton, R. Crumb, Shary Flenniken, Bobby London, Jay Lynch, Kim Deitch. London (New York), 1974.

VV. AA. The apex treasury of underground comics / edited by Susan Goodrick and Don Donahue; featuring, Willie Murphy, Bill Griffith, Art Spiegelman, Spain Rodriguez, Justin Green, Gilbert Shelton, R. Crumb, Shary Flenniken, Bobby London, Jay Lynch, Kim Deitch. The best of Bijou funnies / edited by Jay Lynch; introduction by Marty Pahls; featuring, Jay Lynch, Skip Williamson, Jay Kinney, Justin Green, Robert Crumb, Jim Osborne, Gilbert Shelton, Dan Clyne, Evert Geradts, Rory Hayes, Art Spiegelman and Kim Deitch.The best of Bijou funnies. London, Omnibus Press, 1981.

CuCo, Cuadernos de cómic número 1. Septiembre de 2013 
Widmer, T. "Robert Crumb, The Art of Comics, No.1". The Paris Review (online), 2010. Disponible en http://www.theparisreview.org/interviews/6017/the-art-of-comicsno-1-r-crumb [Comprobado el 11-09-2013] 